\title{
TYPE 2 DIABETES;
}

EFFICACY OF VITAMIN D SUPPLEMENTATION ON GLYCEMIC CONTROL IN TYPE 2 DIABETIC PATIENTS.

1. (MBBS, FCPS Medicine Associate Professor of Medicine), Sheikh Zayed Medical College/ Hospital Rahim Yaar Khan.

2. (MBBS, M. Phil Pharmacology, Assistant professor of Pharmacology),

Sheikh Zayed Medical College/ Hospital Rahim Yaar Khan.

3. (MBBS, Demonstrator Physiology), Sheikh Zayed Medical College/ Hospital Rahim Yaar Khan.

Correspondence Address: Dr. Muhammad Zafar Majeed Babar C-1, Medical Colony

Sheikh Zayed Medical Hospital,

RahimYaar Khan.

mzmbabar@yahoo.co.uk.

Article received on: 17/01/2017

Accepted for publication: 30/04/2017

Received after proof reading: 05/06/2017
Muhammad Zafar Majeed Babar ${ }^{1}$, Mazhar Hussain ${ }^{2}$, Asma Manzur ${ }^{3}$

ABSTRACT... Background: The data among vitamin D supplementation on glycemic control is variable and contradictory in various clinical studies. Objectives: To determine the efficacy of vit D supplementation on glycemic control in type 2 diabetic patients. Study Design: Case control study. Setting: Private Clinical Set up of District, Rahim Yar Khan. Period: August to October 2016. Patients and methods: 100 cases of type 2 diabetes were randomly divided into group $A$ and group $B$ each contained 50 patients. The cases in group A were treated with vitamin D3 at the dose of 50,000 units per week orally while cases in group B were treated with placebo along with the standard doses of anti-diabetic drugs. The value of $\mathrm{HbA} 1 \mathrm{c}$ and Vit $\mathrm{D}$ were assayed pre and post treatment by high performance liquid chromatography. Results: There was significant post treatment changes observed in vitamin $D$ level in group $A$ vs group $B$ in males $20.46 \pm 2.45$ vs $15.16 \pm 1.47(p=0.001)$ and females $18.32 \pm 1.44$ vs $13.95 \pm 2.48(p=0.09)$ There was significant post treatment changes in HbA1c in males $6.65 \pm 0.12$ vs $8.34 \pm 0.71(p=$ $0.01)$ and in females $6.81 \pm 0.43$ vs $8.04 \pm 0.71(p=0.03)$ in group $A$ and group $B$ respectively. Similarly better improvement in vitamin $D$ and $\mathrm{HbA1c}$ level was seen with respect to aged group 30-50 years and duration of diabetes less than 5 years. Conclusion: Vitamin D is deficient in our population and its supplementation not only improves its own level but also glycemic control in type 2 diabetic patients.

Key words: $\quad$ Type II Diabetes mellitus, Vitamin D, HbA1c.

Article Citation: Babar MZM, Hussian M, Manzur A. Type 2 Diabetes; Efficacy of vitamin d supplementation on glycemic control in type 2 diabetic patients. Professional Med J 2017;24(6):899-903. DOI: 10.17957/TPMJ/17.3929

\section{INTRODUCTION}

Diabetes Miletus (DM) is among the most prevalent metabolic syndromes globally. According to an estimate more than 150 million people are labeled with this disease and their number is on the rise day by day and is expected to cross 300 million by the year 2025.1 A strong relationship exists between diabetes and vitamin D. Its low level has a significant contributing role in the initiation, progression as well as complications in the form of myocardial infarction, stroke, retinopathy, neuropathy and nephropathy in diabetic patients in various clinical studies. Therefore multifaceted approach is required to identify diabetes associated vitamin $D$ deficient cases and treat them accordingly in order to reduce disease burden. ${ }^{2-3}$

Vitamin $\mathrm{D}$ is amongst the fat-soluble vitamins in the body and is more than $90 \%$ activated in skin due to sun exposure. Vitamin $D$ acts through vitamin $D$ receptors VRDs which are nuclear receptor and have diverse location in the body that plays a key role in calcium and phosphate metabolism. On the other its adequate level has a protective effects against musculoskeletal disorders, infectious diseases, autoimmune diseases, malignant diseases, cardiovascular diseases, metabolic syndromes, type 1 and type 2 diabetes mellitus, infertility, various respiratory and CNS disorders. ${ }^{4-5}$

Studies showed that polymorphism of the VDRs gene leads to decrease insulin sensitivity, increase insulin resistance and development of type 2 diabetes that leads to increase cardiovascular risk. ${ }^{6-7}$ On the contrary a meta-analysis of 57 case control study concluded that out of the four polymorphism in the VDR gene only BsIm polymorphism have been associated with type 1 
diabetes especially in Asians. Similarly in another meta-analysis there was increased risk of type 2 diabetes mellitus in Asians in Fokl polymorphism of the VDR gene. ${ }^{8-9}$

In spite of satisfactory evidence from genetic studies data about clinical studies is contradicted and controversial. A meta-analysis of seventeen randomized control trials and seven longitudinal studies showed that vitamin $D$ supplementation cannot improve glycemic control in type 2 diabetic patients over a follow up period of one month. ${ }^{10}$ However sunny trial showed that vitamin D supplementation improves glycemic control and quality of life in type 2 diabetic patients over a period of 6 months. ${ }^{11}$ In another systemic review and meta-analysis a favorable effect of vitamin $D$ supplementation on fasting blood sugar in poorly controlled diabetic patients have been identified. ${ }^{12}$ Similarly data from the 21 observational prospective studies and metaanalysis of 12 studies reveals that low level of vitamin is a predisposing factor for development of type 1 and type 2 diabetes and other metabolic diseases. ${ }^{13-14}$

There is need to investigate this doubt as there was no studies conducted in Pakistan up till now to investigate the effect of vitamin D supplementation on glycemic control. So this study was designed to determine the effect of vitamin $D$ effect on glycemic control in type 2 diabetic patients.

\section{PATIENTS AND METHODS}

This case control study was conducted on type 2 diabetic patients aged $30-70$ years at a private clinic of district Rahim Yar Khan, Punjab Pakistan from September to November 2016. Initially 150 patients were recruited out of which 100 patients were enrolled in the study based upon history of diabetes which was confirmed by standard ADA criteria. The patients were excluded if they had neuropathy, nephropathy, retinopathy and hepatic complication associated with diabetes. In addition patients who were taking vitamin D, calcium and any other drugs which effect calcium and vitamin D metabolism such as thiazide \& loop diuretics, bisphosphonates, HRT, calcitonin, and various steroids were excluded from the study.

All the cases which were on oral anti-diabetic drugs were then asked to choose a shield opaque envelope marked as A or B The cases in group A were treated with oral cap vitamin D3 at the dose of 50,000 units weekly for a period of 12 weeks while group $B$ was given cap placebo in a similar manner but it contained microcrystalline cellulose as an active ingredient. BMI was calculated by dividing the weight $(\mathrm{kg}) /$ height $(\mathrm{m} 2)$ without shoes and wearing light clothes. A $5 \mathrm{ml}$ blood sample was calculated from the median cubital vein after an overnight fasting of 12 hours. The samples were used for analyzing $\mathrm{HbA1c}$ and vitamin D level which were estimated in the laboratory by by high performance liquid chromatography.

\section{STATISTICAL ANALYSIS}

Data was analyzed by using statistical package for social sciences SPSS-16. Chi square test was used to compare nominal data and independent sample $t$ test was used to compare the ordinal data. Post stratification independent sample t test was applied to compare the two groups to look for reduction in $\mathrm{HbA1c}$, taking $\mathrm{p}$ value of $\leq 0.05$ as significant.

\section{RESULTS}

No significant major adverse effects were noted during the study and all patients completed the study with nice cooperation. Ten patients in the vitamin $D$ group complaints of minor abdominal bloating during first 2 weeks of therapy which settle down itself without any intervention. There were 50 cases in each group. Group A contained 28 (56\%) males and 22 (44\%) females while Group $B$ had $30(60 \%)$ males and 20 (40\%) females (Table-l) with $p=0.95$. The mean age of group A was $47.38 \pm 5.40$ years while of group B was $45.34 \pm 6.17$ years. Table-II reveals that there was no significant difference in terms of mean age, BMI, duration of $D M$, pre-treatment vit $D$ and $\mathrm{HbA1C}$ level in both groups. On comparison of group A vs $B$ after treatment with vit $D$, the mean Vit $D$ level in males was $20.46 \pm 2.45$ vs $15.16 \pm 1.47(p=0.001)$ while in females it was $18.32 \pm 1.44$ vs $13.95 \pm 2.48$ with $(p=0.09)$ while post treatment $\mathrm{HbA} 1 \mathrm{c}$ in 
males was $6.65 \pm 0.12$ vs $8.34 \pm 0.71 \quad(p=0.01)$ and in females it was $6.81 \pm 0.43$ vs $8.04 \pm 0.71$ $(p=0.03)$ respectively in group $A$ and $B$ as in Table-III. There was also significant improvement in treatment group A where there was significant improvement in terms of Vit D level and HbA1c level in both the groups regarding different age groups and duration of DM and it was better seen in cases with age group 30-50 years and in cases with DM less than 5 years (table-IV \& V).

\begin{tabular}{|l|l|l|l|}
\hline \multicolumn{1}{|c|}{ Variables } & \multicolumn{1}{c|}{ Group A $(\mathbf{N}=\mathbf{5 0})$} & \multicolumn{1}{c|}{ Group B (N=50) } & \multicolumn{1}{c|}{ p value } \\
\hline Male/Female ratio & $30 / 20$ & $28 / 22$ & 0.95 \\
\hline Age (years) & $45.34 \pm 6.17$ & $47.38 \pm 5.40$ & 0.65 \\
\hline BMl (kg/m2) & $28.41 \pm 2.72$ & $26.34 \pm 4.11$ & 0.22 \\
\hline Duration of DM (years) & $9.76 \pm 2.43$ & $11.45 \pm 3.30$ & 0.09 \\
\hline Pre treatment vit D (ng/ml) & $14.15 \pm 3.22$ & $13.26 \pm 2.70$ & 0.97 \\
\hline Pre treatment HbA1c $(\%)$ & $7.96 \pm 1.02$ & $8.15 \pm 0.65$ & 0.14 \\
\hline
\end{tabular}

Table-I. Baseline demographic characteristic of two groups.

\begin{tabular}{|l|l|l|l|l|}
\hline & \multicolumn{1}{|c}{ Gender } & \multicolumn{1}{c|}{ Group A } & \multicolumn{1}{c|}{ Group B } & \multicolumn{1}{c|}{ P value } \\
\hline \multirow{2}{*}{ Post Treatment vit D } & Male & $20.46 \pm 2.45$ & $15.16 \pm 1.47$ & $\mathrm{p}=0.001$ \\
\cline { 2 - 5 } & Female & $18.32 \pm 1.44$ & $13.95 \pm 2.48$ & $\mathrm{p}=0.09$ \\
\hline \multirow{2}{*}{ Post Treatment HbA1c } & Male & $6.65 \pm 0.12$ & $8.34 \pm 0.71$ & $\mathrm{p}=0.01$ \\
\hline & Female & $6.81 \pm 0.43$ & $8.04 \pm 0.71$ & $\mathrm{p}=0.03$ \\
\hline
\end{tabular}

Table-II. Glycemic control with respect to Gender

\begin{tabular}{|l|l|l|l|l|}
\hline & \multicolumn{1}{|c|}{ Age groups } & \multicolumn{1}{c|}{ Group A } & \multicolumn{1}{c|}{ Group B } & \multicolumn{1}{c|}{ P value } \\
\hline \multirow{2}{*}{ Post Treatment vit D } & $30-50$ years & $21.35 \pm 2.92$ & $14.23 \pm 2.56$ & $\mathrm{p}=0.001$ \\
\cline { 2 - 5 } & $>50$ years & $16.33 \pm 2.41$ & $13.55 \pm 2.65$ & $\mathrm{p}=0.03$ \\
\hline \multirow{2}{*}{ Post Treatment HbA1C } & $30-50$ years & $6.25 \pm 0.45$ & $8.04 \pm 0.49$ & $\mathrm{p}=0.0001$ \\
\cline { 2 - 5 } & $>50$ years & $7.06 \pm 0.95$ & $8.06 \pm 0.33$ & $\mathrm{p}=0.04$ \\
\hline
\end{tabular}

Table-III. Glycemic control with respect to age groups.

\begin{tabular}{|l|l|l|l|l|}
\hline & \multicolumn{1}{|c|}{ Duration of DM } & \multicolumn{1}{|c|}{ Group A } & \multicolumn{1}{c|}{ Group B } & \multicolumn{1}{c|}{ Significance } \\
\hline \multirow{2}{*}{ Post Treatment vit D } & $<5$ years & $19.31 \pm 2.47$ & $13.44 \pm 2.48$ & $p=0.002$ \\
\cline { 2 - 5 } & $>5$ years & $16.22 \pm 2.42$ & $14.22 \pm 1.75$ & $p=0.03$ \\
\hline \multirow{2}{*}{ Post Treatment HDA1c } & $<5$ years & $6.35 \pm 1.04$ & $8.02 \pm 0.45$ & $p=0.001$ \\
\cline { 2 - 5 } & $>5$ years & $7.12 \pm 0.94$ & $8.12 \pm 0.55$ & $p=0.04$ \\
\hline
\end{tabular}

Table-IV. Glycemic control with respect to Duration of DM

\section{DISCUSSION}

In this study there was better improvement in terms of $\mathrm{HbA1c}$ in experimental group as compared to control group. This was also seen by different studies in the past that the cases that were treated with vit $D$ had better DM control and had decrease in HbA1c.15-17 The study conducted by Kostoglou-Athanassiou I et al15 found an inverse relationship between the $\mathrm{HbA1c}$ and the vitamin $D$ level that the higher the vit $D$ level and lower is the $\mathrm{HbA1c}$. According to study done by Ochs-Balcom, $\mathrm{H}$ et al and Holick $\mathrm{M}$ et al, the vit $D$ is thought to act on adipose tissue and also increases the sensitivity of insulin in various ways and hence its deficiency can lead to diabetes and vice versa.18-19 The studies have documented that the low vit $D$ level is associated with increased risk of DM in pre diabetic cases and also the risk of gestational DM and its supplementation can decrease their incidence.20-21 However, in other studies done by Liu et al and Pittas et al, the reverse was seen that the cases that took vitamin $D$ had more incidence of metabolic syndromes like Type II DM.22-23 
The reason of it in their study is un explainable. There was also better control in treatment group $B$ where there was significant improvement in terms of Vit D level and HbA1c in both the groups regarding age group 30- 50 years as compared to older age group. This was also seen by the other studies with higher improvement in younger age groups.17,23 However, they did not use the cut off values like our study. The reason of higher control in younger age groups can be due to their active life, so that they are more exposed to sun and the activation of vit $D$ via sunlight can be a factor. Secondly, the social factors of earning and to live with the disease can be another boosting factor to show better compliance towards the treatment. Moreover, physical activity also leads to better glycemic control.

In the present study one more thing was found that the cases with duration of DM less than 5 years had better control. This was also observed by the other studies.24-25 This can be explained by the above mentioned factors as the earlier stage of disease is commoner in young groups. The other factors influencing this, along with the early stage of the disease can be relatively lesser degree of vit deficiencies and enthusiastic approach to manage this complication.

\section{Limitation of Study}

We are unable check markers of insulin sensitivity and resistance such as HOMA-IR and serum insulin level and compare them with $\mathrm{HbA1c}$ and vitamin D. This will give some clearer picture about the action of vitamin $D$ either it increase insulin sensitivity or not. Moreover we cannot rule out confounding environmental factors that strongly effect vitamin D level such as dietary habits, physical activity, seasonal variation and sun exposure.

\section{Future Directions}

A large sample size and long duration studies will be recommended in future

\section{CONCLUSION}

Diabetic patients who are deficient in vitamin $D$, its supplementation have a strong impact on glycemic control in type 2 diabetic patients.

Copyright(C) 30 Apr, 2017.

\section{REFERENCES}

1. Fu J, Prasad HC. Changing epidemiology of metabolic syndrome and type 2 diabetes in Chinese youth. Curr Diab Rep. 2014; 14:447-52.

2. Chakhtoura M, Azar ST. The role of vitamin D deficiency in the incidence, progression and complications of type 1 diabetes mellitus. Int J Endocrinol. 2013.

3. Herrmann M, Sullivan DR, Veillard AS, McCorquodale T, Straub IR, Scott R, Laakso M, Topliss D. Serum 25-hydroxyvitamin D: a predictor of macrovascular and microvascular complications in patients with type 2 diabetes. Diabetes Care. 2015; 38(3):521-528.

4. Pludowski P, Holick MF, Pilz S, Wagner CL, Hollis BW, Grant WB, Shoenfeld Y, Lerchbaum E. Vitamin D effects on musculo skeletal health, immunity, autoimmunity, cardiovascular disease, cancer, fertility, pregnancy, dementia and mortality- a review of recent evidence. Autoimmun Rev.2013; 12(10):976-989.

5. Griz LH, Bandeira F, Gabbay MA, Dib SA, Carvalho EF. Vitamin D and diabetes mellitus: an update 2013. Arq Bras Endocrinol Metabol. 2014; 58(1):1-8.

6. Jain R, Von-Hurst PR, Stonehouse W, Love DR, Higgins $\mathrm{CM}$, Coad J, Association of vitamin $\mathrm{D}$ receptor gene polymorphism with insulin resistance and response to vitamin D. Metabolism. 2012; 61(3):293-301.

7. Sentinelli F, Bertoccini L, Barchetta I, Capoccia D, Incani M, Pani MG, Loche S, Angelico F. Vitamin D receptor(VDR) rs 11568820 variant is associated with type 2 diabetes mellitus and impaired insulin secretion in Italian adults subjects and associates with increased cardio-metabolic risk in children. Nutr Metab Cardiovasc Dis.2016; 26(5):407-413.

8. Zhang J, Li W, Liu J, Wu W, Ouyang H, Zhang Q, Wang $Y$, Liu L. Polymorphism in the vitamin $D$ receptor gene and type 1 diabetes mellitus risk: an update by meta -analysis. Molecular and Cellular Endocrinology.2012; 355(1):135-142.

9. Li L, Wu B, Liu JY, Yang LB. Vitamin D receptor gene polymorphism and type 2 diabetes: a meta-analysis. Archives of Medical Research. 2013; 44(3):235-241.

10. Nigil HN, Anton A, John J, Mittal M. Effect of vitamin D supplementation on glycemic control in patients with type 2 diabetes: a systematic review of interventional studies. J Diab Metabol Dis. 2015; 14:3-7.

11. Krul -Poel YH, Van Wijiland H, Stam F, Ten Boekel 
E, Lips P, Simsek S. Study protocol: a randomized placebo controlled trials to see the effect of vitamin $D$ supplementation on glycemic control in type 2 diabetes mellitus Sunny trial. BMC Endocrine Disorders. 2014; 14(1):59.

12. Krul-Poel YH, Ter Wee MM, Lips P, Simsek S. The effect of vitamin $D$ supplementation on glycemic control in patients with type 2 diabetes mellitus: a systemic review and meta-analysis. Eur J Endocrinol. 2016; 145.

13. Song Y, Wang L, Pittas AG, Del Gobbo LC, Zhang C, Manson JE, Hu FB. Blood 25-hydroxy vitamin D levels and incident type 2 diabetes. Diabetes Care. 2013; 36(5):1422-1428.

14. Shen L, Zhaung QS, Ji HF. Assessment of vitamin D level in type 1 and type 2 diabetes patients: results from meta-analysis. Mol Nutr Food Res. 2016; 60(5):10591067.

15. Kostoglou-Athanassiou I, Athanassiou P, Gkountouvas A, Kaldrymides P. Vitamin D and glycemic control in diabetes mellitus type 2. Ther Adv Endocrinol Metab. 2013; 4(4):122-28.

16. Nasri $\mathrm{H}$, Behradmanesh $\mathrm{S}$, Maghsoudi AR, Ahmadi A, Nasri P, Kopaei MR. Efficacy of supplementary vitamin D on improvement of glycemic parameters in patients with type 2 diabetes mellitus; a randomized double blind clinical trials. J Ren Inj Prev. 2014; 3(1):31-34.

17. Mitri, J, Dawson-Hughes B, Hu F, Pittas A. Effects of vitamin $D$ and calcium supplementation on pancreatic $\beta$ cell function, insulin sensitivity, and glycemia in adults at high risk of diabetes: the Calcium and Vitamin D for Diabetes Mellitus (CaDDM) randomized controlled trial. Am J Clin Nutr. 2011; 94:486-94.
18. Ochs-Balcom $H$, Chennamaneni $R$, Millen A, Shields $P$, Marian $C$, Trevisan $M$, et al. Vitamin $D$ receptor gene polymorphisms are associated with adiposity phenotypes. Am J Clin Nutr. 2011; 93:5-10.

19. Holick M. Evidence-based D-bate on health benefits of vitamin D revisited. Dermatoendocrinology 2012; 4:183-90.

20. Alzaim M, Wood R. Vitamin D and gestational diabetes mellitus. Nutr Rev. 2013; 71:158-67.

21. Lau, S, Gunton J, Athayde N, Byth K, Cheung N. Serum 25-hydroxyvitamin $D$ and glycated haemoglobin levels in women with gestational diabetes mellitus. Med J Aust 2011; 194:334-37.

22. Pittas A, Nelson J, Mitri J, Hillmann W, Garganta C, Nathan D, et al. Plasma 25-hydroxyvitamin D and progression to diabetes in patients at risk for diabetes: an ancillary analysis in the Diabetes Prevention Program. Diabetes Care. 2012; 35:565-73.

23. Liu, S, Song Y, Ford E, Manson J, Buring J, Ridker P. Dietary calcium, vitamin $D$, and the prevalence of metabolic syndrome in middle-aged and older U.S. women. Diabetes Care 2005; 28:2926-32.

24. Pittas A, Dawson-Hughes B, Li T, Van Dam R, Willett W, Manson $\mathrm{J}$, et al. Vitamin $\mathrm{D}$ and calcium intake in relation to type 2 diabetes in women. Diabetes Care 2006; 29:650-56.

25. Heaney R, French C, Nguyen S, Ferreira M, Baggerly $L$, Brunel $L$, et al. A novel approach localizes the association of vitamin d status with insulin resistance to one region of the 25-hydroxyvitamin $D$ continuum. Adv Nutr. 2013; 4:303-10.

\section{AUTHORSHIP AND CONTRIBUTION DECLARATION}

\begin{tabular}{|c|l|l|l|}
\hline Sr. \# & \multicolumn{1}{|c|}{ Author-s Full Name } & \multicolumn{1}{|c|}{ Contribution to the paper } & Author=s Signature \\
\hline 1 & Dr. M. Zafar Majeed Babar & $\begin{array}{l}\text { Conceived the idea } \\
\text { plagiarism, manuscript } \\
\text { review and statistical } \\
\text { analysis. } \\
\text { Designed the study, } \\
\text { preparing the manuscript } \\
\text { and data analysis. } \\
\text { Search the literature, } \\
\text { collected the clinical data, } \\
\text { manuscript editing and } \\
\text { drafting of the manuscript. }\end{array}$ \\
\hline 3 & Dr. Asma Manzur & Dr. Mazhar Hussain & \\
\hline
\end{tabular}

